Check for updates

Cite this: RSC Adv., 2019, 9, 27125

Received 4th May 2019

Accepted 2nd August 2019

DOI: $10.1039 / c 9 r a 03336 j$

rsc.li/rsc-advances

\title{
Tuning the Biginelli reaction mechanism by the ionic liquid effect: the combined role of supported heteropolyacid derivatives and acidic strength $\dagger$
}

\author{
Elon F. Freitas, ${ }^{a}$ Roberto Y. Souza, ${ }^{b}$ Saulo T. A. Passos, (D) ${ }^{b}$ José A. Dias, (D) ${ }^{a}$ \\ Silvia C. L. Dias iD *a and Brenno A. D. Neto (iD *b
}

\begin{abstract}
Herein, a combination of heteropolyacids and ionic liquids as a catalytic system was studied for the Biginelli multicomponent reaction; the positive ionic liquid effect associated with the acidic strength of zeolitesupported heteropolyacids made this combination an efficient catalytic system for the multicomponent synthesis of 3,4-dihydropyrimidin-2(1H)-one/thione derivatives. The acidic strength effect was evaluated, and a range was determined in which the reaction provided better results. The mechanism of the reaction was also investigated in the presence and absence of ionic liquids, and two features of paramount importance were revealed: the mechanism could be tuned to proceed through only one reaction path among three possibilities and the kinetics of the reaction was significantly faster in the presence of an ionic liquid.
\end{abstract}

\section{Introduction}

The search for more sustainable catalytic processes is of paramount importance in modern chemistry. The possibility of merging multicomponent reactions (MCRs) ${ }^{1-3}$ and ionic liquids (ILs) ${ }^{\mathbf{4 - 6}}$ under catalytic conditions is therefore an attractive way to avoid the waste typically observed in linear syntheses and the use of volatile organic solvents. The combination of MCRs and ILs has indeed been regarded as "a perfect synergy for ecocompatible heterocyclic synthesis". ${ }^{7}$

ILs are widely used in the chemical industry, ${ }^{8}$ catalysis, ${ }^{9}$ biocatalysis, ${ }^{10}$ extraction processes, ${ }^{11}$ the obtention and purification of biological components, ${ }^{12}$ and other applications. ${ }^{13}$ For a long time, these ionic fluids have actually been claimed to be the solvents of the future $\mathrm{e}^{\mathbf{1 4 - 1 6}}$ because they represent a plausible alternative towards environmental acceptability. ${ }^{17}$ The use of ILs has proved to be essential to improve yields and/or selectivities in several reactions. ${ }^{\mathbf{1 8 - 2 0}}$ The toolbox of organic methodologies has greatly expanded ever since MCRs have been incorporated as green and sustainable tools. ${ }^{21}$ For example, MCRs are being currently used in polymer modifications, ${ }^{22}$ for fluorescent nanoprobe syntheses, ${ }^{23}$ as AIE luminogens, ${ }^{24}$ as

${ }^{a}$ Laboratory of Catalysis, Chemistry Institute, (IQ-UnB), University of Brasilia, Campus Universitário Darcy Ribeiro - Asa Norte, 70910-900, Brasília-DF, Brazil. E-mail: scdias@unb.br

${ }^{b}$ Laboratory of Medicinal and Technological Chemistry, University of Brasilia, Chemistry Institute (IQ-UnB), Campus Universitário Darcy Ribeiro, 70910-900, Brasília-DF, Brazil. E-mail: brenno.ipi@gmail.com

$\uparrow$ Electronic supplementary information (ESI) available: ESI-MS/MS, NMR spectra and descriptions are provided. See DOI: 10.1039/c9ra03336j metal sensors, ${ }^{25}$ and in straight syntheses of new libraries of biologically active molecules. ${ }^{26}$

The idea of joining MCRs and ILs is in this context promising, and the expectation of achieving better results for MCRs performed in ILs compared to the use of classical organic solvents is more than reasonable. It is known that Brønsted acid catalysts can behave as superacids ${ }^{27,28}$ when supported in ILs. Heteropolyacids (HPAs) naturally display superacid behavior and are currently applied as catalysts in several organic transformations, as reviewed elsewhere. ${ }^{29-31}$ HPAs, both supported and unsupported, have also been tested as catalysts for MCRs. ${ }^{32-37}$

HPA derivatives embedded in IL media have been successfully applied to catalyze some MCRs. ${ }^{36-38}$ For example, a polymeric heteropolyacid-containing pyridinium IL catalyst proved to be a promising system for the multicomponent Biginelli reaction. ${ }^{39}$ The Biginelli reaction is believed by some to be the most important MCR. ${ }^{40}$ This MCR (Scheme 1) allows the direct synthesis of bioactive DHMPs (3,4-dihydropyrimidin-2(1H)ones or -thiones) such as monastrol, piperastrol, and enastron. ${ }^{41-45}$

HPAs and their derivatives have been previously used to promote the Biginelli reaction; however, in general, only moderate yields were achieved using organic solvents and no mechanistic elucidation was described. ${ }^{46}$ The need for excess reagents and other drawbacks, such as organic solvent contamination, low yields, long reaction times and no mechanistic evaluation, were also noted. ${ }^{46-49}$ Some of the authors have investigated different features of the multicomponent Biginelli reaction mechanism ${ }^{50-54}$ and other MCRs $^{55-58}$ as well as heteropolyacid-catalyzed reactions. ${ }^{59-62}$ In the current work, we 

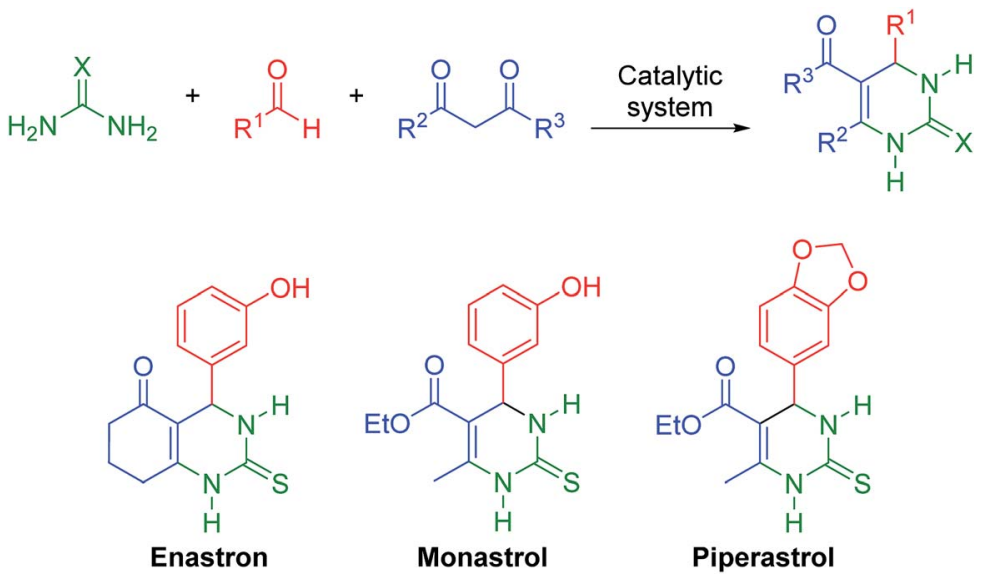

Scheme 1 The general Biginelli reaction and examples of bioactive compounds directly obtained using this multicomponent reaction.

disclose the beneficial effect of ILs using HPA derivatives on the Biginelli reaction and the mechanistic implications for this MCR. For the first time, the reaction pathway of the Biginelli reaction has been tuned by adding an IL to the catalytic system, as will be demonstrated in due course.

\section{Results and discussion}

A comprehensive physicochemical study of the supported HPA catalysts on zeolite $\mathrm{Y}$ tested herein has been published by some of the authors elsewhere ${ }^{59}$ However, some fundamental aspects of those characterizations must be briefly mentioned herein to guide the readers as to the most relevant factors and to associate the structural aspects of the materials with their activity in the tested MCR. Elemental analysis of the HPA supported on zeolite $\mathrm{Y}$ was performed by EDX/XRF. The values obtained were very similar to the nominal ones and were reported as the real values. The XRD results showed increased loss in the crystallinity of the supported catalysts, which was higher for the HPWsupported samples than for the HSiW-supported samples. This is a result of the stronger acidity of HPW, which destroys the zeolite $\mathrm{Y}$ structure in greater proportion during the preparation of the composites. ${ }^{59}$ Dispersion of either HPW or HSiW on the surface of zeolite $\mathrm{Y}$ leads to nanocrystals lower than $20 \mathrm{~nm}$ in size. The fingerprint bands of HPW and HSiW as well as the zeolite Y main bands were verified by FT-IR. The definitive presence of Keggin anions and their interactions with zeolite $\mathrm{Y}$ were confirmed by ${ }^{31} \mathrm{P},{ }^{29} \mathrm{Si}$ and ${ }^{27} \mathrm{Al}$ MAS NMR spectroscopy, which revealed a decrease in tetrahedral $\mathrm{Al}$ as the amount of HPA increased. Gaseous pyridine adsorption experiments indicated that Lewis acid sites from zeolite $\mathrm{Y}$ interacted with the Keggin anions; as a result, the catalysts are heterogeneous in nature. ${ }^{59}$

An initial model Biginelli reaction (Scheme 2 and Fig. 1) using benzaldehyde, urea and ethyl acetoacetate (equimolar quantities) without solvent and in the presence of the catalysts showed that all the HSiW-supported catalysts presented higher yields due to their higher amounts of Brønsted sites than of HPW sites, although they have slightly weaker acid strength. It was observed that pure zeolite Y contains Brønsted acid sites that are not accessible by all reagents ( $18 \%$ yield); therefore, the catalysis occurred on the external surface. On the other hand, the impregnation of HPA caused partial destruction of the crystalline structure of zeolite $\mathrm{Y}$; once deposited on the surface of the zeolite, the strong Brønsted acidic sites (protons) of HPA were exposed, and thus the reaction yield increased. The relative numbers of HPA protons are presented in Table S1 in the ESI. $\dagger$

One parameter that required further evaluation was the reaction temperature. The three best catalysts were chosen, and a temperature range from $50{ }^{\circ} \mathrm{C}$ to $100{ }^{\circ} \mathrm{C}$ was considered (Fig. 2). The catalyst $14 \% \mathrm{HSiW} / \mathrm{Y}$ generally showed lower conversion than the other catalysts. In addition, as the temperature increased, the yields also increased; thus, $100{ }^{\circ} \mathrm{C}$ was chosen as the ideal temperature to perform the MCR.

Next, twelve solvents with different polarities were studied (Fig. 3). In a preliminary run, $95 \%$ yield was achieved for $28 \%$ $\mathrm{HSiW} / \mathrm{Y}$ at $100{ }^{\circ} \mathrm{C}$ using $\mathrm{BMI} \cdot \mathrm{PF}_{6}$ as solvent. When using the imidazolium-based IL BMI $\cdot \mathrm{PF}_{6}$ in a catalyst-free version of the model reaction, the DHPM yield was $35 \%$. In the solvent-free version, but with $28 \% \mathrm{HSiW} / \mathrm{Y}$ as the catalyst, the highest yield was $69 \%$. These results already indicate a positive ionic liquid effect by promoting stabilization of the charged intermediates by the formation of both ion pairs and larger supramolecular aggregates, in accordance with the literature. ${ }^{19,63}$ The presence of the IL increases the reaction rate by decreasing the activation barrier and alters the keto-enol tautomerization equilibrium of ethyl acetate. ${ }^{50}$ The formation of the enol and its stabilization by interactions with the solvent are paramount for the Biginelli reaction because the enolic form is more reactive; literature reports indicate that $\mathrm{BMI} \cdot \mathrm{PF}_{6}$ promotes the tautomeric equilibrium shift to enol formation. ${ }^{50}$

A reaction profile was depicted (Fig. 4). The yields ranged from $16 \%$ to $83 \%$. For both catalysts, the yields were very close within experimental error. After $60 \mathrm{~min}$, the yield became steady, presenting little variation. An approximately sigmoid profile could be observed because the product precipitates from the reaction medium, thus shifting the equilibrium towards 
<smiles>CCOC(=O)CC(C)=O</smiles><smiles>C[As](=O)(=O)[Hg]C(N)=O</smiles><smiles>CCOC(=O)C1=C(C)NC(=O)NC1c1ccccc1</smiles>

Scheme 2 The model Biginelli reaction used to optimize the catalytic conditions in this study. All reactions were performed using equimolar quantities of the reagents.

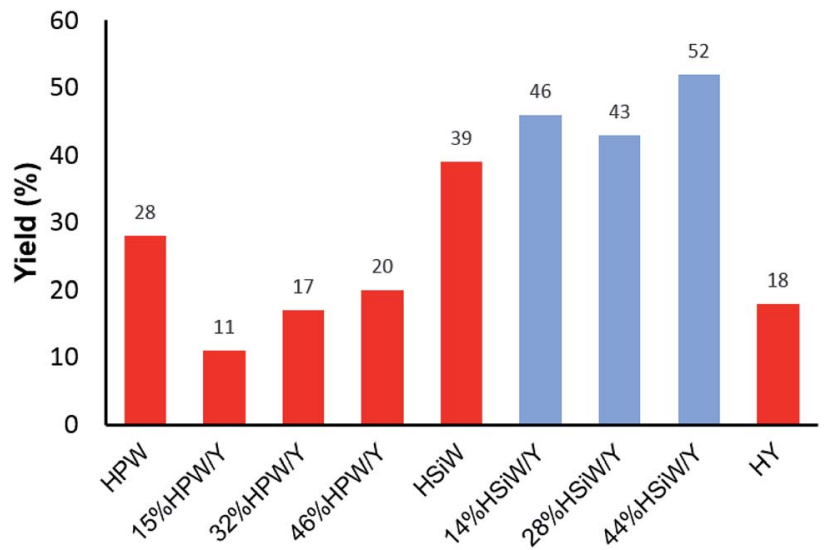

Fig. 1 Effects of the catalyst composition on the reaction yield of the solvent-free model Biginelli reaction ( $1 \mathrm{mmol}$ of each reagent) with a catalyst load of $30 \mathrm{mg}$ after $60 \mathrm{~min}$ at $90^{\circ} \mathrm{C}$.

MCR adduct formation; this is in accordance with the expected profile as indicated in another study. ${ }^{50}$

Further evaluation of the catalyst amount revealed that $50 \mathrm{mg}$ of catalyst presented the best yields for both $28 \% \mathrm{HSiW} / \mathrm{Y}$ and $44 \% \mathrm{HSiW} / \mathrm{Y}$ (Fig. 5).

Thus, based on the optimization results for the Biginelli reaction, we noted that the best catalysts were $28 \% \mathrm{HSiW} / \mathrm{Y}$ and $44 \% \mathrm{HSiW} / \mathrm{Y}$. Previous analyse ${ }^{59}$ of the acidities of these catalysts showed that $28 \% \mathrm{HSiW} / \mathrm{Y}$ had sites as strong as $123 \mathrm{~kJ} \mathrm{~mol}^{-1}$ in an amount of $0.06 \mathrm{mmol} \mathrm{g}^{-1}$ of catalyst, whereas $44 \% \mathrm{HSiW} / \mathrm{Y}$ had stronger sites $\left(137 \mathrm{~kJ} \mathrm{~mol}^{-1}\right)$ with
$0.05 \mathrm{mmol} \mathrm{g}^{-1}$ of acid sites. At this point, for good performance of this reaction, acidic sites within 120 to $140 \mathrm{~kJ} \mathrm{~mol}^{-1}$ were necessary. Otherwise, the yield for these reactions decreased, which indicates the occurrence of possible parallel reactions that lead to the decomposition of the main product and reagents. These results are in accordance with the literature, ${ }^{52}$ where superacidic systems led to decomposition of the reagents and the adduct of the Biginelli reaction. Considering the nature of the acidic sites of the catalysts used herein, it is shown that the Lewis sites of the original zeolite $\mathrm{Y}$ were practically eliminated by the introduction of HSiW on its surface. Because HSiW is located mainly at the pore mouths of zeolite $\mathrm{Y}$, the acid sites accessed by the substrates were those on the deposited nanocrystals. The Brønsted sites were therefore responsible for the catalytic Biginelli reaction. ${ }^{59}$ An in-depth analytical characterization of the best catalytic zeolite-supported heteropolyacid is shown in Fig. S1-S8 in the ESI. $\dagger$

The best catalytic conditions could therefore be compared with other catalytic systems already described in the literature for the multicomponent Biginelli reaction, as shown in Table 1. It should be noted that the other procedures using zeolites or heteropolyacids (or both) require longer times and excess reagents and return lower yields in typically longer reaction times. Solvent has been proved to play a vital role to further the Biginelli reaction under catalyzed conditions; ${ }^{64}$ thus, solventless conditions are not the best option for this MCR. Some examples noted in Table 1 require toxic solvents, such as toluene or acetonitrile.

The current methodology allowed the DHPM derivative to be obtained in almost quantitative yield using the ionic fluid

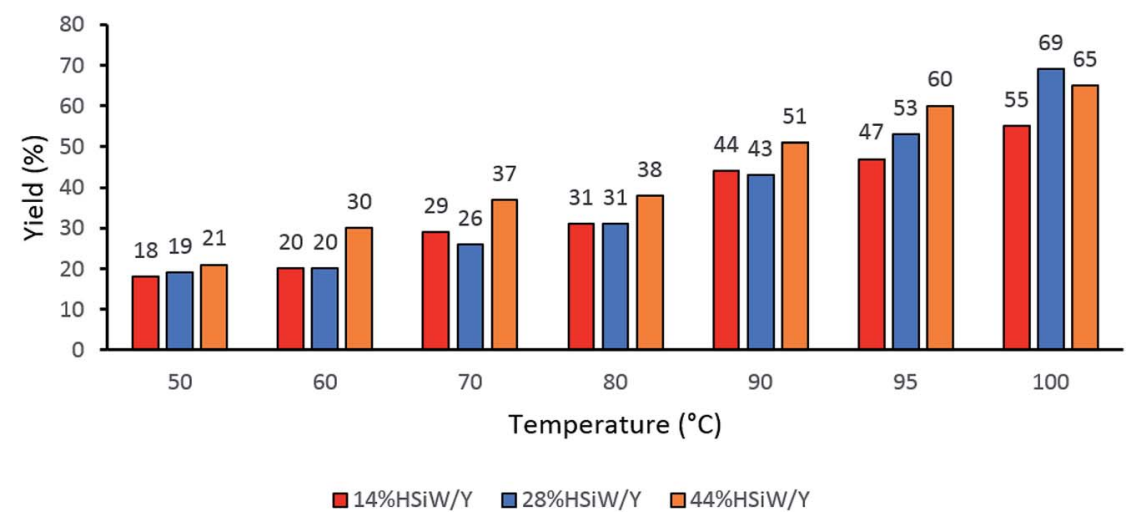

Fig. 2 Effects of the reaction temperature on the solvent-free model Biginelli reaction yields. Reaction time of $60 \mathrm{~min}$ with $30 \mathrm{mg}$ of catalyst, $1 \mathrm{mmol}$ of each reagent and no solvent. 


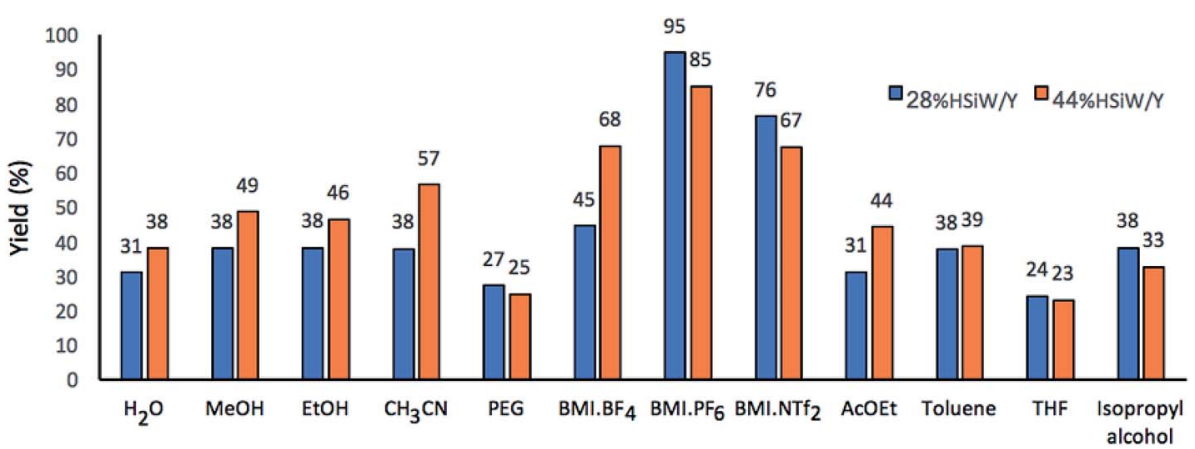

Fig. 3 Effects of the solvent on the yield of the model Biginelli reaction. Reaction time of 60 min, 30 mg of catalyst, temperature of $100{ }^{\circ} \mathrm{C}$, $1 \mathrm{mmol}$ of each reagent and $0.5 \mathrm{~mL}$ of solvent. All reactions were performed in sealed Schlenk tubes to avoid solvent loss.

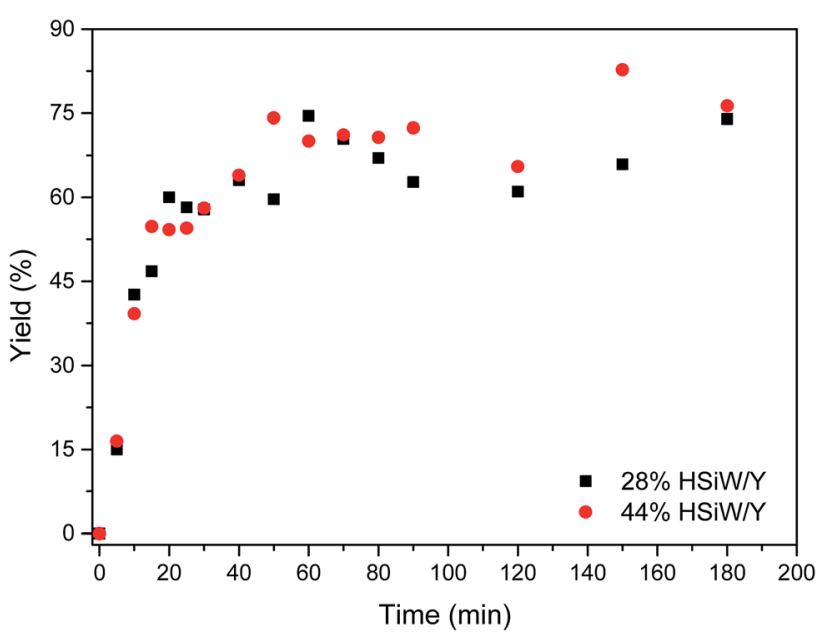

Fig. 4 Kinetic profile for the catalytic model Biginelli reaction under the following conditions: temperature of $100{ }^{\circ} \mathrm{C}, 1 \mathrm{mmol}$ of each reagent, $30 \mathrm{mg}$ of catalyst and $0.5 \mathrm{~mL}$ of the solvent $\mathrm{BMI} \cdot \mathrm{PF}_{6}$. All yields refer to the isolated DHPM derivative.

$\mathrm{BMI} \cdot \mathrm{PF}_{6}$ as the reaction medium. Equimolar quantities of reagents were required, and no excess reagents were needed to obtain the DHPM in nearly quantitative yield. The reaction time of only $60 \mathrm{~min}$ is among the shortest times reported for the reaction. The catalytic system could also be recovered and reused at least three times. The following yields were obtained: $99 \%, 70 \%$ and $75 \%$, respectively. The washing procedure using ethanol to purify the Biginelli adduct (see the Experimental section for details) is likely responsible for the catalyst mass loss throughout the purification; after the third cycle, only $40 \mathrm{mg}$ of the solid catalyst was recovered, indicating $20 \%$ mass loss during recycling.

To gain insight into the generality of the methodology, the best system $(28 \% \mathrm{HSiW} / \mathrm{Y})$ was used to perform the synthesis of other DHPM derivatives. The results are summarized in Table 2.

Good to excellent yields were generally obtained for the isolated DHPMs, indicating the good performance of the best catalytic system under the optimized reaction conditions. Compounds with known antitumoral activities ${ }^{74}$ (Table 2, entries b, c, d and g) could be directly obtained using the developed methodology.

The mechanism of the reaction was also investigated by electrospray (tandem) mass spectrometry ${ }^{75}$ (ESI-MS(/MS)). ESI has been successfully used to disclose several mechanistic aspects of a plethora of catalyzed and noncatalyzed reactions, as discussed in several reviews. ${ }^{76-83}$ The Brønsted acid-catalyzed Biginelli reaction mechanism was first disclosed by ESI monitoring by Eberlin and co-workers. ${ }^{84}$ Later, we demonstrated the

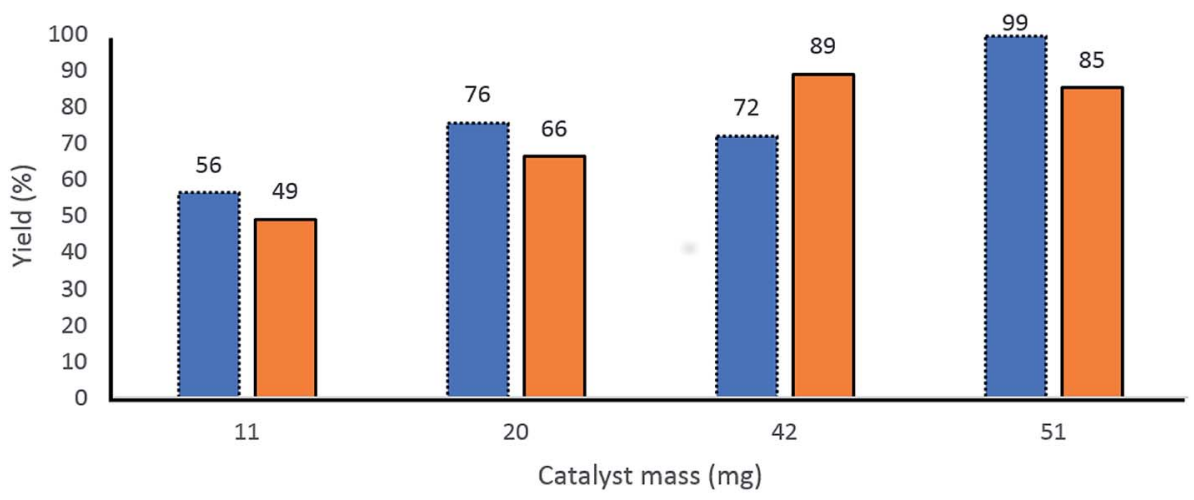

: $28 \% \mathrm{HSIW} / \mathrm{Y} \quad \square 44 \% \mathrm{HSIW} / \mathrm{Y}$

Fig. 5 Effect of the catalyst amount on the yields of the model Biginelli reaction. Reaction time of $60 \mathrm{~min}$, temperature of $100{ }^{\circ} \mathrm{C}, 1 \mathrm{mmol}$ of each reagent, $0.5 \mathrm{~mL}$ of $\mathrm{BMI} \cdot \mathrm{PF}_{6}$. 
Table 1 Comparison of the catalytic system developed herein and previously reported literature conditions

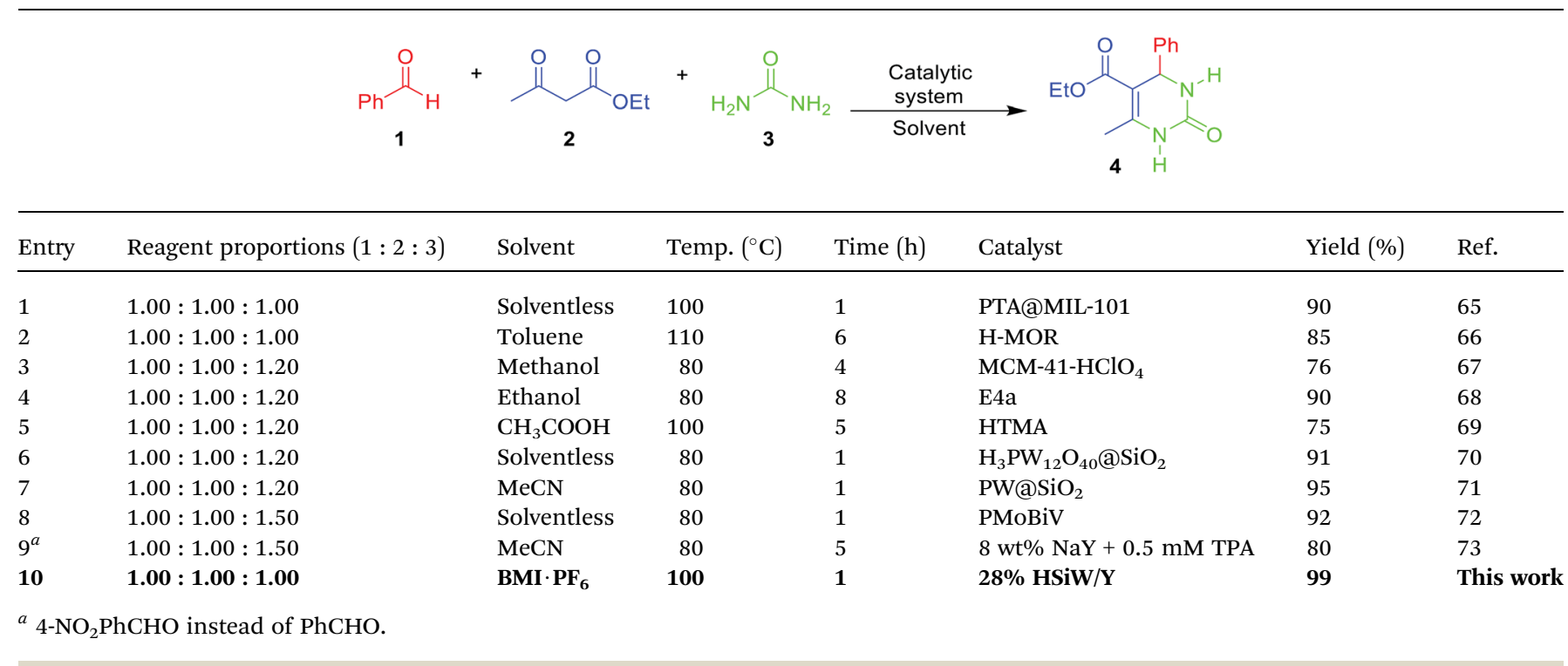

Lewis acid-catalyzed Biginelli reaction mechanism ${ }^{53}$ and some variations of Brønsted acid-catalyzed reactions. ${ }^{50-52}$ Basically, three mechanisms may occur at the same time; ${ }^{56}$ that is, the iminium, Knoevenagel and enamine pathways (Scheme 3). The formation of the first key intermediate determines the reaction pathway, although the reactions may take place in a complex equilibrium. ${ }^{85}$ Typically, the iminium mechanism is favored, as shown in many available studies. ${ }^{6,86}$ Some catalytic conditions, however, favor the Knoevenagel mechanism ${ }^{\mathbf{8 7}, \mathbf{8 8}}$ or the enamine pathway. ${ }^{89,90}$ In some cases, more than one mechanism may be operating at the same time, even under catalyzed conditions. ${ }^{91}$ Due to the high complexity of the mechanism, its evaluation is an enormous challenge.

To evaluate the influence of the IL on the reaction, the analyses were monitored online during 5, 30, 60 and $90 \mathrm{~min}$ in the absence and in the presence of the ionic medium (Fig. 6).

Table 2 Biginelli reaction promoted by $28 \% \mathrm{HSiW} / \mathrm{Y}(50 \mathrm{mg})$ as the catalyst in $\mathrm{BMI} \cdot \mathrm{PF}_{6}(0.5 \mathrm{~mL})$. The reactions were performed with $1.00 \mathrm{mmol}$ of each reagent at $100{ }^{\circ} \mathrm{C}$ for $60 \mathrm{~min}$

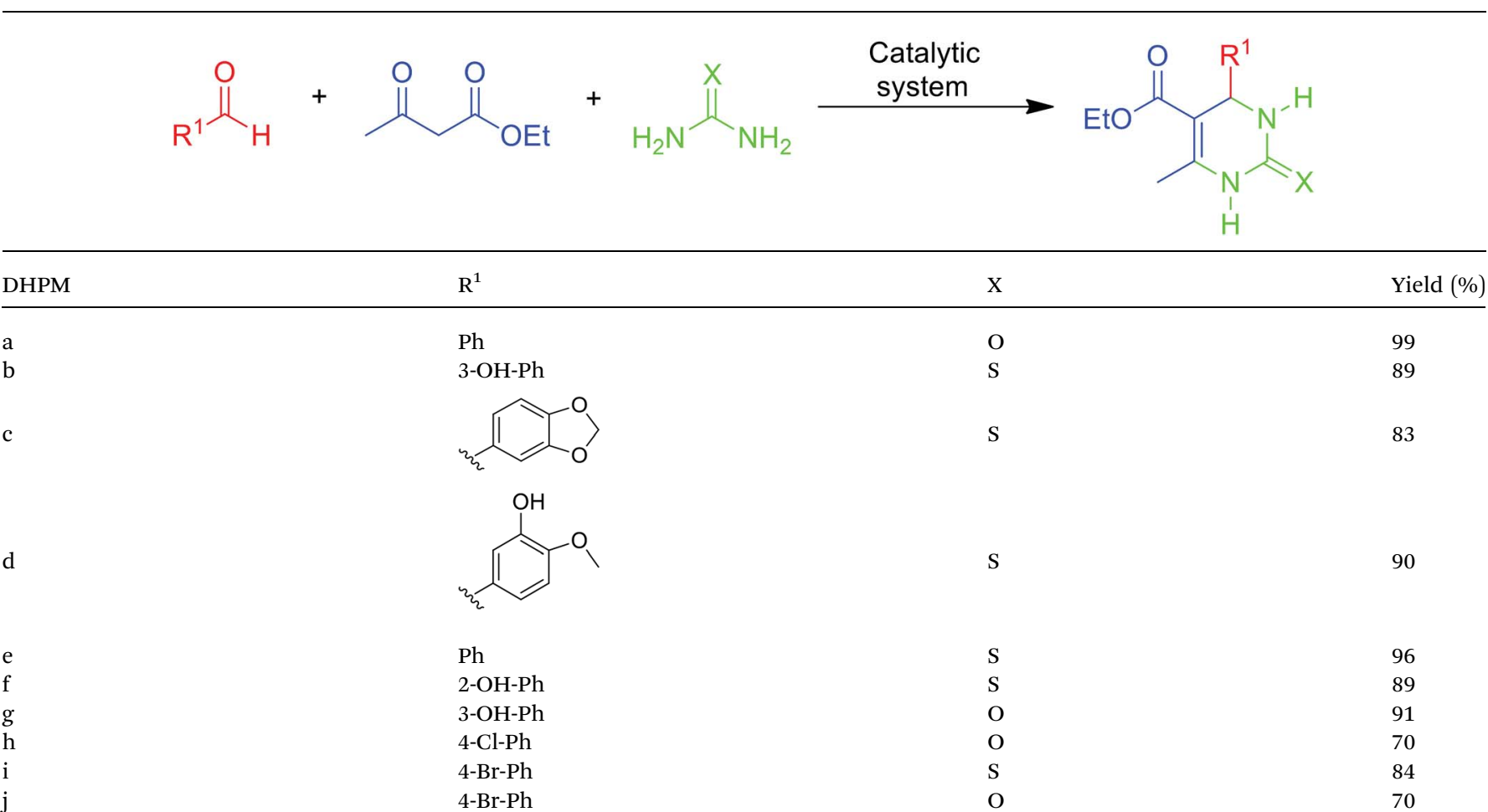


The ESI(+)-MS/MS characterization of all detected intermediates is presented in Fig. S9-S15 in the ESI. $\dagger$

For the reaction monitored online in the absence of the IL (Fig. 6-I), the presence of a signal attributed to the iminium mechanism was noted (intermediate of $m / z$ 149), although a Knoevenagel intermediate $(\mathrm{m} / \mathrm{z} 241)$ and the enamine intermediate $(\mathrm{m} / \mathrm{z} 173)$ could also be detected (Fig. 6D-I) and were further characterized by tandem MS/MS (Fig. S3 and S5 $\dagger$ ). This indicates that at least three mechanisms may be occurring at the same time, and it is not possible to identify any preference of the reaction pathway. It was also noted that the intermediate of $\mathrm{m} / \mathrm{z} 301$ (detected as a sodiated adduct) formed immediately after the addition of 1,3-dicarbonyl to the iminium ion $(\mathrm{m} / \mathrm{z}$ 149); this in turn undergoes cyclization, affording the Biginelli adduct ( $\mathrm{m} / \mathrm{z} 261$ or $\mathrm{m} / \mathrm{z} 283$ as the sodiated adduct). After $90 \mathrm{~min}$ of reaction (Fig. 6D-I) in the absence of the IL, the intermediates are noted at high intensity, and the base peak is an intermediate of $m / z 301$. In the initial period of the reaction ( $5 \mathrm{~min}$, Fig. 6A-I), the base peak is the iminium intermediate (seen as the adduct of $m / z 231)$.

For the reaction conducted in the presence of the IL BMI $\cdot \mathrm{PF}_{6}$ $(0.5 \mu \mathrm{M})$, a completely different reaction profile is depicted in
Fig. 6-II. The Knoevenagel intermediate $(\mathrm{m} / \mathrm{z} 241)$ appears to be the key intermediate during the whole transformation. In the beginning of the reaction (Fig. 6B-II), the iminium intermediate is also noted; however, the unsuccessful detection during the time course of the reaction clearly indicates that the iminium is reversibly formed and returns to the reagents (equilibrium), therefore proceeding preferentially through the Knoevenagel pathway (Fig. 6D-II). Another important feature is that the reaction is apparently faster in the presence of the ionic salt. After $5 \mathrm{~min}$ of reaction (Fig. 6A-II), the base peak is the last intermediate $(\mathrm{m} / \mathrm{z} 301)$ prior to the Biginelli adduct formation $(\mathrm{m} / \mathrm{z} 261$ or 283), and at the end of the reaction (Fig. 6D-II), the imidazolium cation $(\mathrm{m} / \mathrm{z} 139)$ is the base peak. To confirm this supposition, the monitoring was repeated using $5 \mu \mathrm{M}$ of the IL concentration (Fig. 7); after 5 min, only the imidazolium and the Biginelli adduct were detected, and almost no intermediate could be noted except for the last intermediate $(\mathrm{m} / \mathrm{z} 301)$ formed prior to the cyclization step, affording the expected DHPM $(\mathrm{m} / \mathrm{z}$ 261). This result strongly indicates the positive effect of the IL during the catalyzed reaction.

We also decided to monitor the reaction using 4-chloro benzaldehyde as the reagent (see Table 2, Entry h) because it

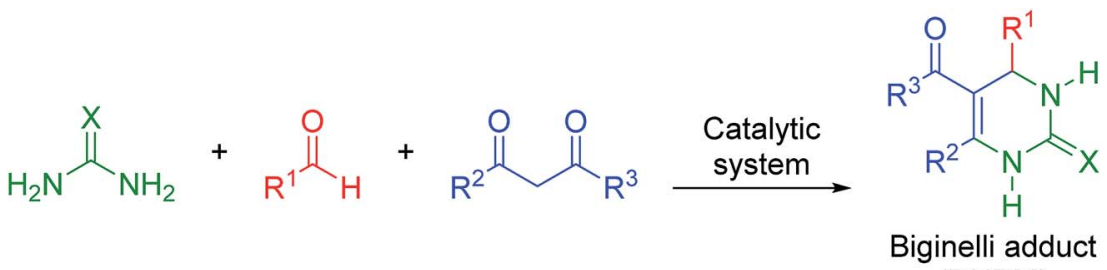

(DHPM)

Iminium mechanism

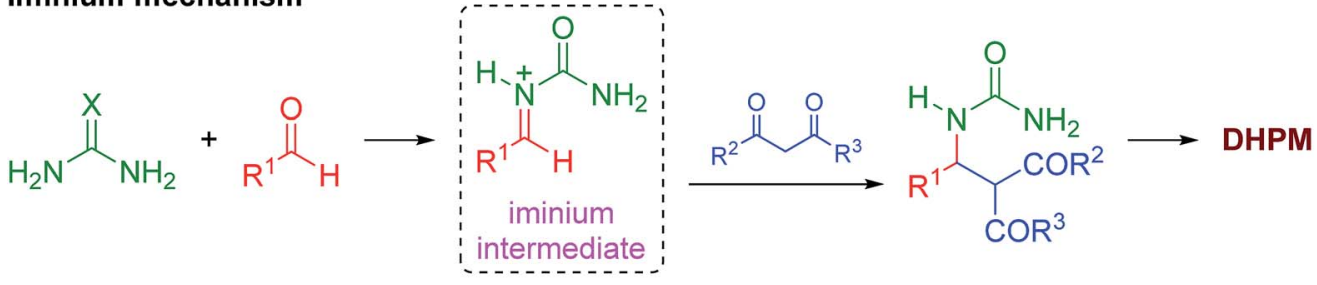

Knoevenagel mechanism<smiles>[R]C(=O)CC([R7])=O</smiles><smiles>[R]C(=O)C(C(=O)O)C(=O)O</smiles>

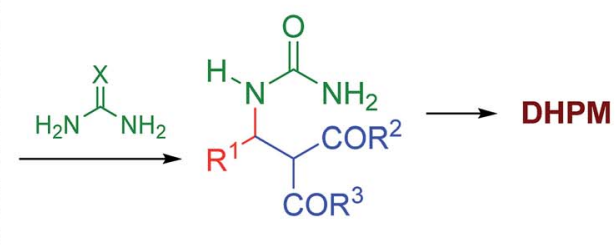

\section{Enamine mechanism}<smiles>[R]C(=O)CC([R])=O</smiles>

Scheme 3 The catalyzed Biginelli reaction and the three simplified possible reaction pathways for DHPM formation. 
Paper

View Article Online

RSC Advances
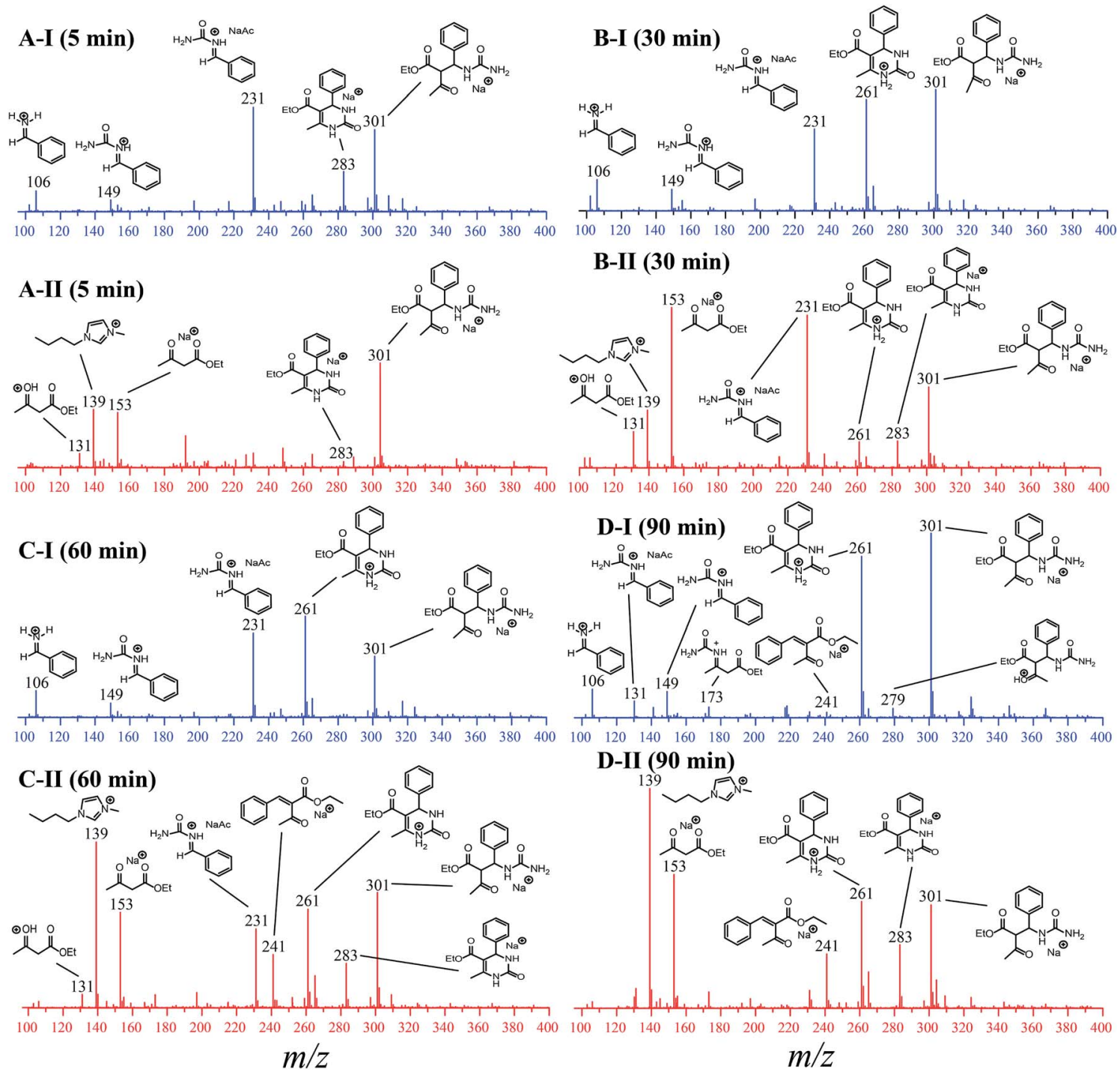

Fig. $6 \mathrm{ESI}-\mathrm{MS}(+)$ monitoring of the Biginelli reaction in the absence (I, blue spectra) and presence (II, red spectra) of the ionic liquid $\mathrm{BMI} \cdot \mathrm{PF}_{6}$. (A)

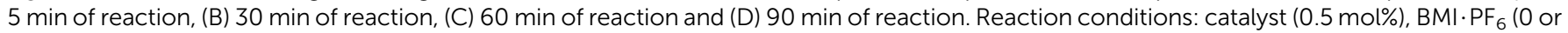
$0.5 \mu \mathrm{M})$, benzaldehyde $(5.0 \mu \mathrm{M})$, ethyl acetoacetate $(5.0 \mu \mathrm{M})$, urea $(5.0 \mu \mathrm{M})$. The analyses were performed by dissolving the reaction mixture in methanol to afford the described concentrations.

returned the lowest yield among all the synthesized DHPMs. In principle, this experiment should allow us to verify both the mechanism and the possibility of intermediate (and/or byproduct) formation and should increase our comprehension of the transformation along with the catalytic behavior of the developed system, as shown in Fig. S16. $\dagger$

The time monitoring of the reaction returned interesting results and showed no detectable enamine intermediate $(\mathrm{m} /$ $z$ 173). Starting reagent signals (see Fig. S16†) were also noted during the reaction monitoring time; however, no characterizable intense byproduct signal was detected, indicating that no side reactions were taking place. These results helped to explain the lower observed yields during the synthesis of this DHPM derivative because the reagents were not fully consumed but no notable byproduct formed.
The Knoevenagel intermediate $(\mathrm{m} / \mathrm{z} 253$ using the 4-chloro benzaldehyde instead of benzaldehyde), although noted in the spectra after $30 \mathrm{~min}$ of reaction monitoring, had a very low intensity, thus preventing its MS/MS characterization. However, the iminium intermediate $(\mathrm{m} / \mathrm{z} 183)$ could be noted during the whole time course of the reaction, and its signal intensity could be monitored (Fig. 8).

As depicted in Fig. 8, the iminium intermediate concenration increased during the reaction course. This result has two important implications: (i) the yield is expected to be lower because the intermediate is increasing in concentretimon instead of being consumed, as expected during the course of a MCR. Therefore, this intermediate shows the behavior of a so-called dead-end intermediate. ${ }^{57,92}$ (ii) The results point once more to the Knoevenagel pathway

This journal is @) The Royal Society of Chemistry 2019

RSC Adv., 2019, 9, 27125-27135 | 27131 


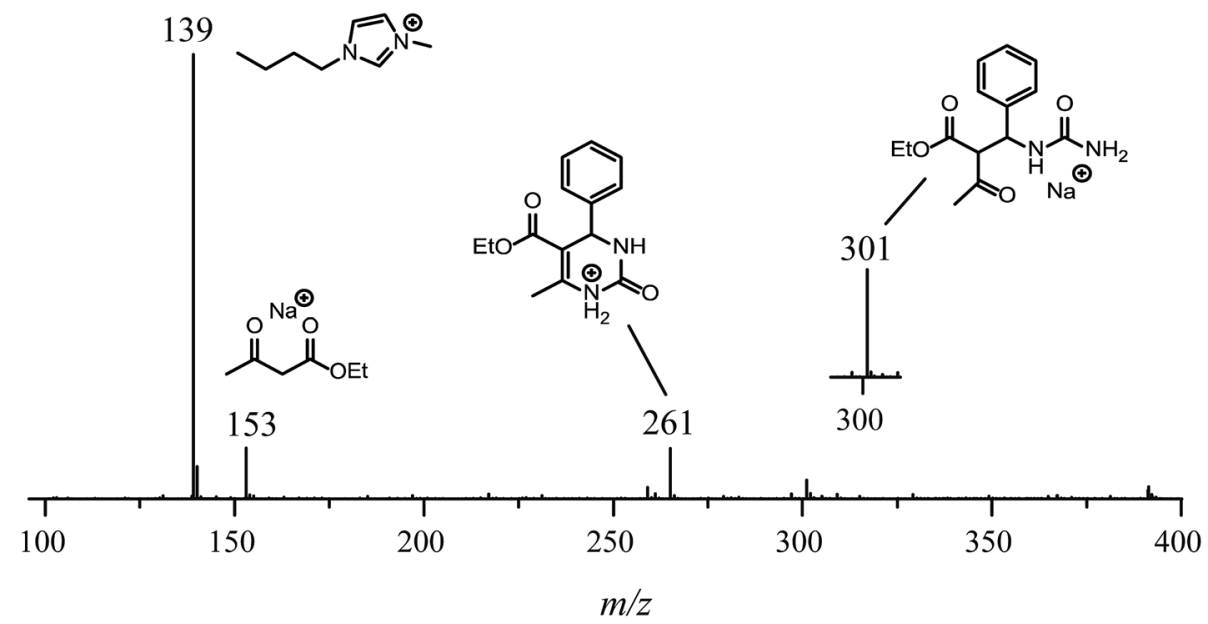

Fig. $7 \mathrm{ESI}-\mathrm{MS}(+)$ monitoring of the Biginelli reaction in the presence of the ionic liquid $\mathrm{BMI} \cdot \mathrm{PF}_{6}$ after 5 min of reaction. Reaction conditions: catalyst $(0.5 \mathrm{~mol} \%), \mathrm{BMI} \cdot \mathrm{PF}_{6}(5.0 \mu \mathrm{M})$, benzaldehyde $(5.0 \mu \mathrm{M})$, ethyl acetoacetate $(5.0 \mu \mathrm{M})$, and urea $(5.0 \mu \mathrm{M})$. The analyses were performed by dissolving the reaction mixture in methanol to afford the described concentrations. The inset is a 12 -fold expansion to show the intermediate of $\mathrm{m} / \mathrm{z} 301$ prior to the final cyclization step affording the Biginelli adduct.

because this intermediate was detected and readily consumed, as expected for the preferentially operating Biginelli reaction pathway.

Based on all the obtained results, a catalytic cycle can be proposed (Scheme 4) in the presence and in the absence of the imidazolium-based IL $\mathrm{BMI} \cdot \mathrm{PF}_{6}$. In the presence of $\mathrm{BMI} \cdot \mathrm{PF}_{6}$, the Knoevenagel pathway seems to be highly favored. The cationic intermediates are also prone to afford ion pairs and larger supramolecular aggregates when both the anion and the cation are present in the reaction. In the absence of the IL, the three reaction pathways are likely to be involved in the DHPM synthesis; this indicates that the positive IL effect not only improves the yield and shortens the reaction time, but also affects the selection of the reaction pathway. Although the iminium mechanism seems to be preferentially acting in the catalysis without ILs, the presence of intermediates from the other two possible mechanisms indicates that the catalytic system is not capable of selecting only one pathway and suppressing the possibilities of the other two; this is a key feature that is observed when the catalysis is performed in the ionic medium.

In summary, a method has been developed to perform the Biginelli reaction in combination with HPAs and the limits of the acidic strength have been demonstrated. The use of zeolites as supports for HPA derivatives is an effective strategy for the development of new catalytic systems to be applied in several acid-catalyzed MCRs. The best catalytic system developed herein $(28 \% \mathrm{HSiW} / \mathrm{Y})$ could be applied under optimized conditions to the synthesis of several DHPMs, including some with known antitumoral activities.

The mechanism investigation by means of ESI-MS(/MS) indicated that the three possible mechanisms occur at the same time when the reaction is performed in the absence of the IL. In the presence of the IL, however, the reaction pathway can be tuned, and only one mechanism operates during the catalytic DHPM synthesis. For the first time, the mechanism pathway selection was successfully tuned simply by carrying out the reaction in an IL; this is in accordance with the positive IL effects noted for several previously described catalyzed reactions (see the cited reviews). The results described herein open an avenue of possibilities toward more efficient catalyzed MCRs and show the advantages of merging heteropolyacids and ILs not only for improving yields and shortening reaction times, but also for possibly improving the selectivity and tuning the reaction pathways during a chemical transformation.

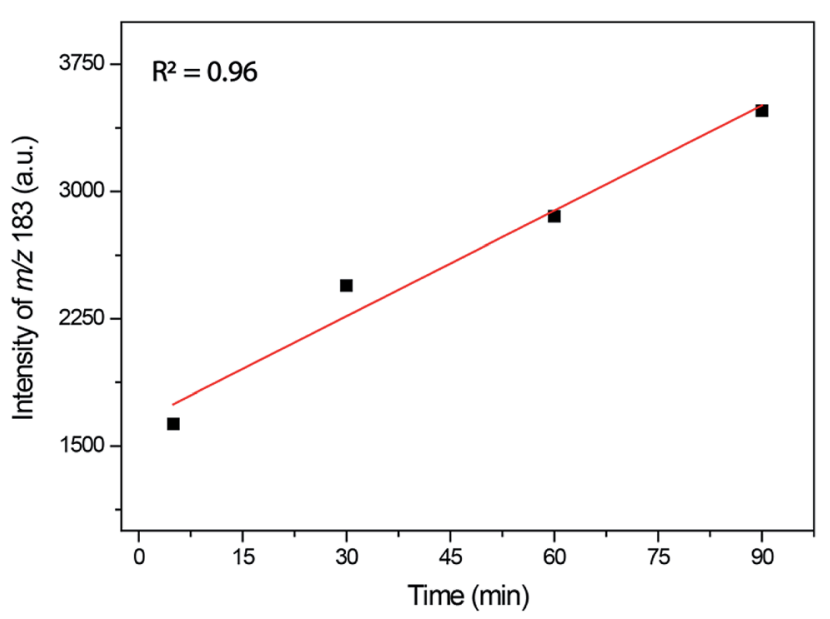

Fig. 8 Monitoring of the iminium intermediate $(\mathrm{m} / \mathrm{z} 183)$ by ESI $(+)-\mathrm{MS}$ during the reaction time. Reaction conditions: catalyst $(0.5 \mathrm{~mol} \%)$, $\mathrm{BMI} \cdot \mathrm{PF}_{6}(5.0 \mu \mathrm{M})$, 4-chloro benzaldehyde $(5.0 \mu \mathrm{M})$ instead of benzaldehyde, ethyl acetoacetate $(5.0 \mu \mathrm{M})$, and urea $(5.0 \mu \mathrm{M})$. The analyses were performed by dissolving the reaction mixture in methanol to afford the described concentrations. 


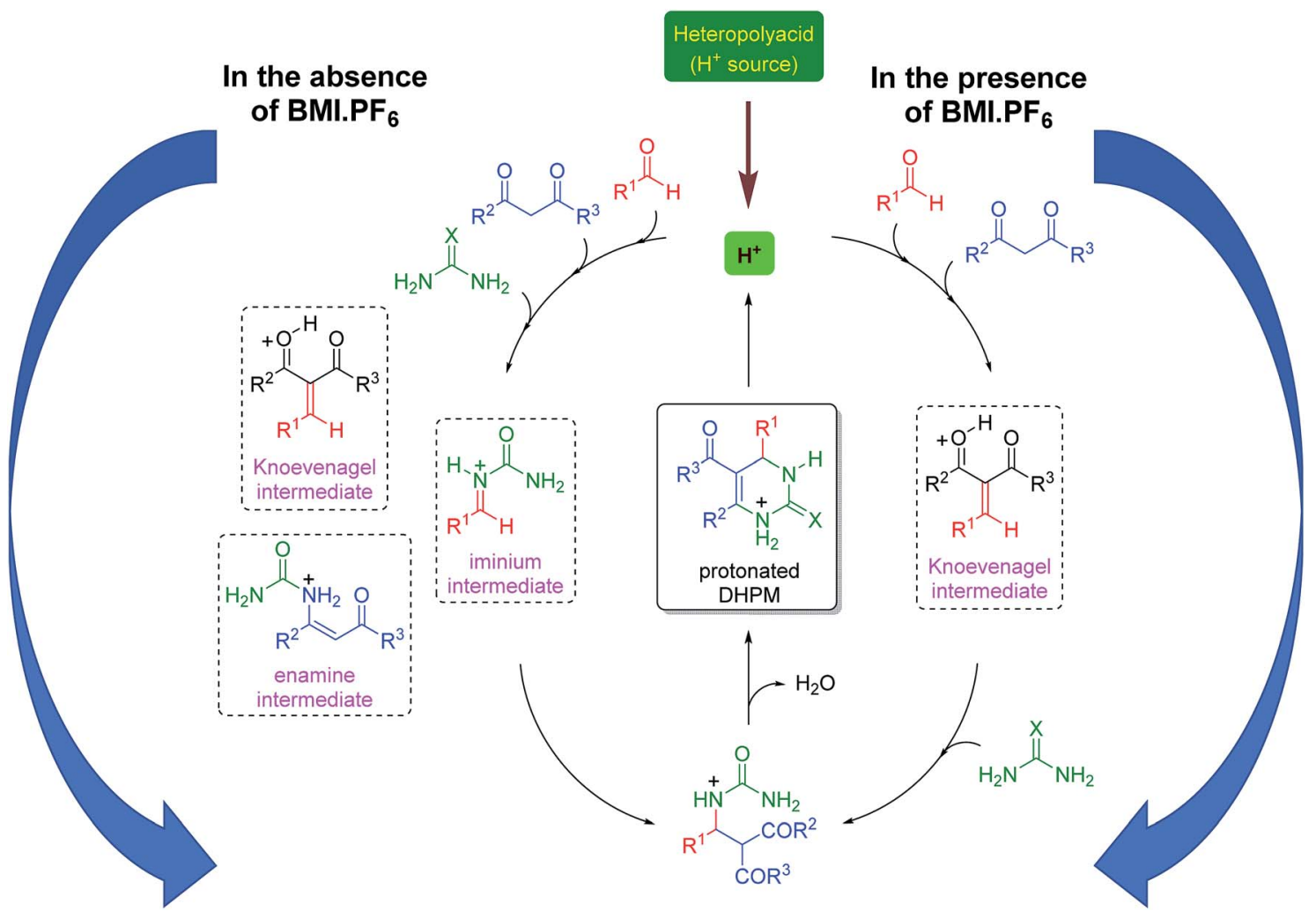

Scheme 4 Catalytic cycle in the presence (right) and absence (left) of BMI.PF ${ }_{6}$. Note that in the presence of the ionic fluid, only one pathway is favored, whereas in its absence, three pathways are likely to be involved.

\section{Experimental}

\section{Preparation of the supported HPAs}

$\mathrm{NH}_{4}$-Y zeolite from Zeolyst $\left(\mathrm{CBV} 300, \mathrm{SiO}_{2} / \mathrm{Al}_{2} \mathrm{O}_{3}\right.$ molar ratio $=$ 5.1) was calcined at $5500^{\circ} \mathrm{C}$ for $8 \mathrm{~h}$ to obtain the protonic form (HY). HPA impregnation was performed in aqueous solution using $1 \mathrm{~g}$ of $\mathrm{HY}$ added to $10 \mathrm{~mL}$ of a $0.1 \mathrm{~mol} \mathrm{~L}^{-1} \mathrm{HCl}$ solution containing the required amount of HPA $(15,30$, and $45 \mathrm{wt} \%$ $\mathrm{H}_{3} \mathrm{PW}_{12} \mathrm{O}_{40}$, HPW or $\mathrm{H}_{4} \mathrm{SiW}_{12} \mathrm{O}_{40}$, HSiW, Aldrich, >99.9\%). The slurry was maintained under stirring at $150{ }^{\circ} \mathrm{C}$ until solvent evaporation. Then, the catalysts were treated in a furnace at $300{ }^{\circ} \mathrm{C}$ for $4 \mathrm{~h}$ (denoted as $\mathrm{X} \% \mathrm{HPA} / \mathrm{Y}$ ).

\section{Characterization of the catalysts}

Detailed conditions of the characterization have been published elsewhere. ${ }^{59}$ A general description is provided here for reference. The real amounts of the supported HPAs on the HY samples were obtained by elemental analysis using an EDX-XRF spectrometer from Shimadzu (model EDX 720). The quantity of HPA was determined by tungsten elemental analysis using analytical curves. XRD patterns were obtained with a Bruker powder diffractometer (model D8 Focus) using a copper tube $(\mathrm{K} \alpha=1.5406 \AA)$ in the $2 \theta$ region from 2 to $50^{\circ}$. FT-IR spectra were obtained on a Thermo Scientific (model Nicolet 6700) spectrometer. Samples were prepared by the KBr pellet method $(1: 100$ - sample : KBr). The nature of the acid sites was determined by FT-IR spectroscopy of pyridine adsorbed on the catalysts. All acquisitions were obtained at $25^{\circ} \mathrm{C}$, with 256 scans and $4 \mathrm{~cm}^{-1}$ resolution. Magic angle spinning solid state nuclear magnetic resonance (MAS NMR) spectroscopy was performed on a Bruker Avance III HD, Ascend $\left(600 \mathrm{MHz}\right.$ for $\left.{ }^{1} \mathrm{H}\right)$ at $14.1 \mathrm{~T}$, using a $4 \mathrm{~mm} \mathrm{CP} / \mathrm{MAS}$ probe in zirconia rotors. ${ }^{31} \mathrm{P}(243.1 \mathrm{MHz})$, ${ }^{29} \mathrm{Si}(119.3 \mathrm{MHz})$ and ${ }^{27} \mathrm{Al}(156.4 \mathrm{MHz})$ nuclei at a spin rate of 10 $\mathrm{kHz}$ were used to characterize the catalysts. The strengths (enthalpy) of the catalysts were measured by liquid phase incremental microcalorimetry of pyridine in cyclohexane slurries. For the calcined samples $\left(300{ }^{\circ} \mathrm{C}\right)$ of HPA supported on zeolite $\mathrm{Y}$, a diluted pyridine solution in cyclohexane was added to the solid slurry in anhydrous cyclohexane, and the amount of evolved heat was determined.

\section{Catalytic reactions}

The reactants benzaldehyde and ethyl acetoacetate were purified by distillation, and no treatment was performed on commercial urea. All catalysts were activated by heating treatment at $300{ }^{\circ} \mathrm{C}$ for $1 \mathrm{~h}$ before being used in the reaction. The standard experiment was run in a sealed Schlenk tube, in which $50 \mathrm{mg}$ of catalyst was weighed and then $1 \mathrm{mmol}$ of each reagent was added. $0.5 \mathrm{~mL}$ of $\mathrm{BMI} \cdot \mathrm{PF}_{6}$ was added to the system. The tube was then sealed and maintained under magnetic stirring for $60 \mathrm{~min}$ at $100{ }^{\circ} \mathrm{C}$. The Biginelli adducts were purified by crystallization using hot ethanol. If no precipitation was noted, the crude mixture was purified by a chromatographic column 
using mixtures of hexane and ethyl acetate. All product characterizations are shown in the ESI. $\dagger$

\section{Conflicts of interest}

There are no conflicts to declare.

\section{Notes and references}

1 A. Domling, W. Wang and K. Wang, Chem. Rev., 2012, 112, 3083-3135.

2 B. H. Rotstein, S. Zaretsky, V. Rai and A. K. Yudin, Chem. Rev., 2014, 114, 8323-8359.

3 L. Levi and T. J. J. Mueller, Chem. Soc. Rev., 2016, 45, 28252846.

4 J. Dupont, Acc. Chem. Res., 2011, 44, 1223-1231.

5 J. P. Hallett and T. Welton, Chem. Rev., 2011, 111, 3508-3576.

6 J. Dupont, R. F. de Souza and P. A. Z. Suarez, Chem. Rev., 2002, 102, 3667-3691.

7 N. Isambert, M. D. S. Duque, J. C. Plaquevent, Y. Genisson, J. Rodriguez and T. Constantieux, Chem. Soc. Rev., 2011, 40, 1347-1357.

8 N. V. Plechkova and K. R. Seddon, Chem. Soc. Rev., 2008, 37, 123-150.

9 J. M. Balbino, D. Peral, J. Carles Bayon and J. Dupont, ChemCatChem, 2015, 7, 972-977.

10 F. vanRantwijk and R. A. Sheldon, Chem. Rev., 2007, 107, 2757-2785.

11 F. Pena-Pereira and J. Namiesnik, ChemSusChem, 2014, 7, 1784-1800.

12 H. Tateishi-Karimata and N. Sugimoto, Nucleic Acids Res., 2014, 42, 8831-8844.

13 O. Acevedo, J. Phys. Chem. A, 2014, 118, 11653-11666.

14 R. D. Rogers and K. R. Seddon, Science, 2003, 302, 792-793.

15 K. R. Seddon, Nat. Mater., 2003, 2, 363-365.

16 M. J. Earle and K. R. Seddon, Pure Appl. Chem., 2000, 72, 1391-1398.

17 M. Petkovic, K. R. Seddon, L. P. N. Rebelo and C. S. Pereira, Chem. Soc. Rev., 2011, 40, 1383-1403.

18 J. W. Lee, J. Y. Shin, Y. S. Chun, H. Bin Jang, C. E. Song and S.-G. Lee, Acc. Chem. Res., 2010, 43, 985-994.

19 H. K. Stassen, R. Ludwig, A. Wulf and J. Dupont, Chem.-Eur. J., 2015, 21, 8324-8335.

20 F. Fuenzalida, D. Aravena, C. Garcia, M. Garcia, R. Arce, G. Ramirez, C. Diaz, M. Isaacs, M. del Carmen Arevalo and M. J. Aguirre, Electrochim. Acta, 2017, 258, 959-969.

21 R. C. Cioc, E. Ruijter and R. V. A. Orru, Green Chem., 2014, 16, 2958-2975.

22 R. Kakuchi, Angew. Chem., Int. Ed., 2014, 53, 46-48.

23 Z. Long, L. C. Mao, M. Y. Liu, Q. Wan, Y. Q. Wan, X. Y. Zhang and Y. Wei, Polym. Chem., 2017, 8, 5644-5654.

24 T. T. Hao, H. R. Liang, Y. H. Ou-Yang, C. Z. Yin, X. L. Zheng, M. L. Yuan, R. X. Li, H. Y. Fu and H. Chen, J. Org. Chem., 2018, 83, 4441-4454.

25 J. J. Yang, J. R. Li, P. F. Hao, F. D. Qiu, M. X. Liu, Q. Zhang and D. X. Shi, Dyes Pigm., 2015, 116, 97-105.
26 P. Slobbe, E. Ruijter and R. V. A. Orru, MedChemComm, 2012, 3, 1189-1218.

27 C. Chiappe and S. Rajamani, Eur. J. Org. Chem., 2011, 55175539.

28 K. E. Johnson, R. M. Pagni and J. Bartmess, Monatsh. Chem., 2007, 138, 1077-1101.

29 L. M. Sanchez, H. J. Thomas and G. P. Romanelli, Mini-Rev. Org. Chem., 2015, 12, 115-126.

30 F. Su and Y. H. Guo, Green Chem., 2014, 16, 2934-2957.

31 G. P. Romanelli and J. C. Autino, Mini-Rev. Org. Chem., 2009, 6, 359-366.

32 P. I. Villabrille, V. Palermo, A. G. Sathicq, P. G. Vazquez and G. P. Romanelli, Curr. Org. Chem., 2018, 22, 94-100.

33 S. Sadjadi, M. M. Heravi, V. Zadsirjan and V. Farzaneh, Appl. Surf. Sci., 2017, 426, 881-889.

34 V. Palermo, A. G. Sathicq, T. Constantieux, J. Rodriguez, P. G. Vazquez and G. P. Romanelli, Catal. Lett., 2016, 146, 1634-1647.

35 V. Palermo, A. Sathicq, T. Constantieux, J. Rodriguez, P. Vazquez and G. Romanelli, Catal. Lett., 2015, 145, 10221032.

36 S. M. Sadeghzadeh, RSC Adv., 2016, 6, 75973-75980.

37 R. Tayebee, M. F. Abdizadeh, B. Maleki and E. Shahri, J. Mol. Liq., 2017, 241, 447-455.

38 M. M. Heravi, M. Mirzaei, S. Y. S. Beheshtiha, V. Zadsirjan, F. M. Ameli and M. Bazargan, Appl. Organomet. Chem., 2018, 32, e4479.

39 J. K. Wang, Y. X. Zong, R. G. Fu, Y. Y. Niu, G. R. Yue, Z. J. Quan, X. C. Wang and Y. Pan, Ultrason. Sonochem., 2014, 21, 29-34.

40 F. S. De Oliveira, P. M. De Oliveira, L. M. Farias, R. C. Brinkerhoff, R. C. M. A. Sobrinho, T. M. Treptow, C. R. Montes D'Oca, M. A. G. Marinho, M. A. Hort, A. P. Horn, D. Russowsky and M. G. Montes D'Oca, MedChemComm, 2018, 9, 1282-1288.

41 D. Russowsky, R. F. S. Canto, S. A. A. Sanches, M. G. M. D'Oca, A. de Fatima, R. A. Pilli, L. K. Kohn, M. A. Antonio and J. E. de Carvalho, Bioorg. Chem., 2006, 34, 173-182.

42 H. Y. K. Kaan, V. Ulaganathan, O. Rath, H. Prokopcova, D. Dallinger, C. O. Kappe and F. Kozielski, J. Med. Chem., 2010, 53, 5676-5683.

43 M. Oliverio, P. Costanzo, M. Nardi, I. Rivalta and A. Procopio, ACS Sustainable Chem. Eng., 2014, 2, 1228-1233.

44 D. Russowsky, F. A. Lopes, V. S. S. da Silva, K. F. S. Canto, M. G. M. D'Oca and M. N. Godoi, J. Braz. Chem. Soc., 2004, 15, 165-169.

45 M. N. Godoi, H. S. Costenaro, E. Kramer, P. S. Machado, M. G. Montes D'Oca and D. Russowsky, Quim. Nova, 2005, 28, 1010-1013.

46 L. Saher, M. Makhloufi-Chebli, L. Dermeche, B. BoutemeurKhedis, C. Rabia, A. M. S. Silva and M. Hamdi, Tetrahedron Lett., 2016, 57, 1492-1496.

47 J. S. Yadav, B. V. S. Reddy, P. Sridhar, J. S. S. Reddy, K. Nagaiah, N. Lingaiah and P. S. Saiprasad, Eur. J. Org. Chem., 2004, 552-557. 
48 M. M. Heravi, F. Derikvand and F. F. Bamoharram, J. Mol. Catal. A: Chem., 2005, 242, 173-175.

49 M. M. Heravi, K. Bakhtiari and F. F. Bamoharram, Catal. Commun., 2006, 7, 373-376.

50 H. G. O. Alvim, T. B. Lima, A. L. de Oliveira, H. C. B. de Oliveira, F. M. Silva, F. C. Gozzo, R. Y. Souza, W. A. da Silva and B. A. D. Neto, J. Org. Chem., 2014, 79, 3383-3397.

51 L. M. Ramos, B. C. Guido, C. C. Nobrega, J. R. Corrêa, R. G. Silva, H. C. B. de Oliveira, A. F. Gomes, F. C. Gozzo and B. A. D. Neto, Chem.-Eur. J., 2013, 19, 4156-4168.

52 H. G. O. Alvim, T. B. de Lima, H. C. B. de Oliveira, F. C. Gozzo, J. L. de Macedo, P. V. Abdelnur, W. A. Silva and B. A. D. Neto, ACS Catal., 2013, 3, 1420-1430.

53 L. M. Ramos, A. Tobio, M. R. dos Santos, H. C. B. de Oliveira, A. F. Gomes, F. C. Gozzo, A. L. de Oliveira and B. A. D. Neto, J. Org. Chem., 2012, 77, 10184-10193.

54 G. C. O. Silva, J. R. Correa, M. O. Rodrigues, H. G. O. Alvim, B. C. Guido, C. C. Gatto, K. A. Wanderley, M. Fioramonte, F. C. Gozzo, R. de Souza and B. A. D. Neto, RSC Adv., 2015, 5, 48506-48515.

55 G. A. Medeiros, W. A. da Silva, G. A. Bataglion, D. A. C. Ferreira, H. C. B. de Oliveira, M. N. Eberlin and B. A. D. Neto, Chem. Commun., 2014, 50, 338-340.

56 H. G. O. Alvim, E. N. da Silva Junior and B. A. D. Neto, RSC Adv., 2014, 4, 54282-54299.

57 R. Y. Souza, G. A. Bataglion, D. A. C. Ferreira, C. C. Gatto, M. N. Eberlin and B. A. D. Neto, RSC Adv., 2015, 5, 7633776341.

58 H. G. O. Alvim, G. A. Bataglion, L. M. Ramos, A. L. de Oliveira, H. C. B. de Oliveira, M. N. Eberlin, J. L. de Macedo, W. A. da Silva and B. A. D. Neto, Tetrahedron, 2014, 70, 3306-3313.

59 E. F. Freitas, M. F. Paiva, S. C. L. Dias and J. A. Dias, Catal. Today, 2017, 289, 70-77.

60 F. C. G. de Mattos, E. N. C. B. de Carvalho, E. F. de Freitas, M. F. Paiva, G. F. Ghesti, J. L. de Macedo, S. C. L. Dias and J. A. Dias, J. Braz. Chem. Soc., 2017, 28, 336-347.

61 P. R. S. Braga, A. A. Costa, E. F. de Freitas, R. O. Rocha, J. L. de Macedo, A. S. Araujo, J. A. Dias and S. C. L. Dias, J. Mol. Catal. A: Chem., 2012, 358, 99-105.

62 C. F. Oliveira, L. M. Dezaneti, F. A. C. Garcia, J. L. de Macedo, J. A. Dias, S. C. L. Dias and K. S. P. Alvim, Appl. Catal., A, 2010, 372, 153-161.

63 T. S. Rodrigues, V. H. C. Silva, P. M. Lalli, H. C. B. de Oliveira, W. A. da Silva, F. Coelho, M. N. Eberlin and B. A. D. Neto, J. Org. Chem., 2014, 79, 5239-5248.

64 J. H. Clark, D. J. Macquarrie and J. Sherwood, Chem.-Eur. J., 2013, 19, 5174-5182.

65 M. Saikia, D. Bhuyan and L. Saikia, Appl. Catal., A, 2015, 505, 501-506.

66 S. R. Mistry, R. S. Joshi, S. K. Sahoo and K. C. Maheria, Catal. Lett., 2011, 141, 1541-1547.

67 K. Khan and Z. N. Siddiqui, Monatsh. Chem., 2015, 146, 2097-2105.
68 A. Hegedus, Z. Hell and I. Vigh, Synth. Commun., 2006, 36, 129-136.

69 M. Tajbakhsh, B. Mohajerani, M. M. Heravi and A. N. Ahmadi, J. Mol. Catal. A: Chem., 2005, 236, 216-219.

70 M. M. Amini, A. Shaabani and A. Bazgir, Catal. Commun., 2006, 7, 843-847.

71 E. Rafiee and F. Shahbazi, J. Mol. Catal. A: Chem., 2006, 250, 57-61.

72 O. D'alessandro, A. G. Sathicq, V. Palermo, L. M. Sanchez, H. Thomas, P. Vázquez, T. Constantieux and G. Romanelli, Curr. Org. Chem., 2012, 16, 2763-2769.

73 M. Moosavifar, C. R. Chim., 2012, 15, 444-447.

74 A. de Fatima, T. C. Braga, L. d. S. Neto, B. S. Terra, B. G. F. Oliveira, D. L. da Silva and L. V. Modolo, J. Adv. Res., 2015, 6, 363-373.

75 F. Coelho and M. N. Eberlin, Angew. Chem., Int. Ed., 2011, 50, 5261-5263.

76 L. S. Santos, J. Braz. Chem. Soc., 2011, 22, 1827-1840.

77 R. Theron, Y. Wu, L. P. E. Yunker, A. V. Hesketh, I. Pernik, A. S. Weller and J. S. McIndoe, ACS Catal., 2016, 6, 69116917.

78 C. Iacobucci, S. Reale and F. De Angelis, Angew. Chem., Int. Ed., 2016, 55, 2980-2993.

79 J. Limberger, B. C. Leal, A. L. Monteiro and J. Dupont, Chem. Sci., 2015, 6, 77-94.

80 K. L. Vikse, Z. Ahmadi and J. S. McIndoe, Coord. Chem. Rev., 2014, 279, 96-114.

81 A. Ray, T. Bristow, C. Whitmore and J. Mosely, Mass Spectrom. Rev., 2018, 37, 565-579.

82 L. P. E. Yunker, R. L. Stoddard and J. S. McIndoe, J. Mass Spectrom., 2014, 49, 1-8.

83 C.-C. Chen and P.-C. Lin, Anal. Methods, 2015, 7, 6947-6959.

84 R. De Souza, E. T. da Penha, H. M. S. Milagre, S. J. Garden, P. M. Esteves, M. N. Eberlin and O. A. C. Antunes, Chem.Eur. J., 2009, 15, 9799-9804.

85 B. A. D. Neto, H. G. O. Alvim and A. A. M. Lapis, in Noncovalent Interactions in Catalysis, The Royal Society of Chemistry, 2019, ch. 17, pp. 377-392.

86 C. O. Kappe, J. Org. Chem., 1997, 62, 7201-7204.

87 C. G. S. Lima, S. Silva, R. H. Goncalves, E. R. Leite, R. S. Schwab, A. G. Correa and M. W. Paixao, ChemCatChem, 2014, 6, 3455-3463.

88 K. Folkers and T. B. Johnson, J. Am. Chem. Soc., 1933, 55, 3784-3791.

89 I. Cepanec, M. Litvic, M. Filipan-Litvic and I. Grungold, Tetrahedron, 2007, 63, 11822-11827.

90 M. Litvic, I. Vecenaj, Z. M. Ladisic, M. Lovric, V. Vinkovic and M. Filipan-Litvic, Tetrahedron, 2010, 66, 3463-3471.

91 S. H. Zheng, Y. J. Jian, S. Xu, Y. Wu, H. M. Sun, G. F. Zhang, W. Q. Zhang and Z. W. Gao, RSC Adv., 2018, 8, 8657-8661.

92 V. G. Santos, M. N. Godoi, T. Regiani, F. H. S. Gama, M. B. Coelho, R. O. M. A. de Souza, M. N. Eberlin and S. J. Garden, Chem.-Eur. J., 2014, 20, 12808-12816. 